\title{
Role of diagnostic laparoscopy in infertility
}

\author{
Divyesh N. Panchal*, Ami Shah
}

Assistant Professor, Department of Obstetrics and Gynecology, GCS Medical College, Hospital and Research centre, Ahmedabad, Gujarat, India

Received: 20 October 2016

Accepted: 25 October 2016

\section{*Correspondence:}

Dr. Divyesh N. Panchal,

E-mail: divyeshpanchal9@gmail.com

Copyright: ( ) the author(s), publisher and licensee Medip Academy. This is an open-access article distributed under the terms of the Creative Commons Attribution Non-Commercial License, which permits unrestricted non-commercial use, distribution, and reproduction in any medium, provided the original work is properly cited.

\begin{abstract}
Background: Use of diagnostic and therapeutic laparoscopy in infertility has been a focus of attention in recent years and demonstrated to be very effective method in evaluating these cases. The main objective of the study was to detect the diagnostic efficacy of laparoscopy in uterine, pelvic and ovarian pathologies.

Methods: This prospective study included 50 infertile women and it was conducted at department of Obstetrics and Gynaecology, Smt. N.H.L. Municipal Medical College, Ellisbridge, Ahmedabad during the period between May 2006 to November 2008. After thorough gynecological examination, necessary investigations were made and written consent form was taken from them before laparoscopy. The patients were kept fasting for 24 hours before the laparoscopy and the procedure was performed under general anaesthesia. All the data was collected on pre-designed proforma and the results were tabulated and raw percentages calculated to describe the results.

Results: Among 50 patients, 34 were of primary infertility cases and 16 were of secondary infertility. In primary infertility maximum number of patient belonged to age group of 21-25 years where as secondary infertility were under the age group $26-30$ years and above 31 years of age. In primary infertility $65 \%$ patients had active marriage life duration of $2-4$ years, while in secondary infertility cases $81 \%$ of patients had marriage life age of more than 6 years. Out of 50 patients, $14(28 \%)$ had absolutely normal laparoscopic findings. Among the various pathologies observed, ovarian pathology contributed the most (36\%), followed by tubal (26\%), pelvic (22\%) and uterine (10\%) pathologies.

Conclusions: Laparoscopy is safe and cost effective method and should be considered as prime diagnostic tool for evaluating the etiology of infertility in women and for effective treatment decisions.
\end{abstract}

Keywords: Infertility, Laparoscopy, Primary and secondary infertility

\section{INTRODUCTION}

Infertility is well-defined as failure to conceive during one year of unprotected frequent intercourse. ${ }^{1}$ The problem of infertility was affecting approximately $9-16 \%$ of married couples. ${ }^{2}$ Leading causes of infertility include tubal disease, ovulatory disorders, uterine or cervical factors, endometriosis and male factor infertility. ${ }^{3,4}$ Major instigates according to WHO are pelvic tuberculosis, malnutrition and puerperal infections leading to tubal blockage. $^{5,6}$
The traditional method to determine the pelvic cavity was hysterosalpingography but it has now been largely succeeded by hysteroscopy and laparoscopy. Diagnostic laparoscopy was found to be the safe and cost effective in the initial management of young women with infertility, particularly when infertility treatment dropout rates exceed $9 \%$ per cycle. ${ }^{7}$ It allows direct visualisation of the abdominal and pelvic organs where clinical evaluation and imaging techniques have failed or are equivocal. Thus, it is considered as an important tool not only in diagnosis of infertility but also in the treatment of selected cases. ${ }^{8}$ 
In the present study, an effort was made to establish the role of laparoscopy in primary and secondary infertility cases in women and to detect the diagnostic efficacy of laparoscopy in uterine, pelvic and ovarian pathologies.

\section{METHODS}

This prospective study included 50 cases of both primary and secondary infertility in woman. The study was carried out during the period from May 2006 to November 2008 at department of Obstetrics and Gynaecology, Smt. N.H.L. Municipal Medical College, Ellisbridge, Ahmedabad. After thorough gynecological examination and with all necessary investigations (human semen analysis, baseline endocrinal investigations, post coital study, cervical mucus study, ovulation study, post menstrual HSG) patients were admitted a day before surgery.

Written consent form was taken from all the patients. All the patients were kept fasting after $10 \mathrm{pm}$ a day before surgery. Enema was given in morning at 6:00 am. They were advised to void completely before entering the operation room. The diagnostic laparoscopies were performed under general anaesthesia with endotracheal intubation and were maintained on gas, oxygen and halothane.

A bimanual pelvic examination under general anesthesia is done. After measuring uterocervical length Rubins cannula was fixed in position by holding cervix transversely with tenaculum. Cannula was useful for moving internal organ and for patency test as well as for the correction of retroverted uterus. Pneumoperitoneum was created using carbon dioxide gas (inert, safest, readily absorbable, not supporting combustion) through veress needle inserted through lower border of umbilicus keeping in mind not to choose an area adjacent to previous laparotomy scar for fear of damage to adherent bowel. The optimal sign for a successful puncture of abdominal skin is a soft listing sound as the needle enters. The gas flow rate was kept at 1 liter/minute and approx. 1-1.5 liter gas was required for diagnostic laparoscopy to maintain pressure of $12 \mathrm{~mm} \mathrm{Hg}$ inside the peritoneal cavity. If the needle is attached to carbon dioxide pneumoapparatus, with the machine closed and abdominal wall is elevated a negative pressure indicates correct placement of needle. Pneumoperitoneum should be considered adequate when the abdominal wall is uniformly bulging and the liver dullness is obliterated. The trocar cannula is pushed in at 45 degrees with screwing movement after lifting the lower abdominal wall. The cannula is removed and laparoscope was introduced. The pelvic organs are first inspected by manipulating uterus, tubes, ovaries, pouch of Douglas are visualized for any pathology. Chromopertubation was done to check the patency of tubes by injecting dilute methylene blue through the intrauterine cannula. Any endometriotric implant is ruled out by thorough examination. Double puncture technique is more reliable to rule out pelvic pathology. After completion of procedure, laparoscope is removed and trocar sleeve is kept open to remove air from abdominal cavity. The trocar is introduced and trocar cannula is removed. The skin was sutured and sterile dressing was done. After completion of procedure the patients was shifted toward when they are completely out of anaesthesia. They were discharged on the next day. The parameters to be monitored were decided and recorded accordingly.

\section{RESULTS}

Our study included 50 patients. Of them, 34 patients were of primary infertility cases and 16 were of secondary infertility. Majority patients of infertility are $70 \%$ between the ages of 21-30 years. In primary infertility cases maximum number of patient $(36 \%)$ belonged to age group of 21-25 years whereas maximum number of secondary infertility cases were not under the age group of 26-30 years as given in Table 1.

Table 1: Age group of patients with primary and secondary infertility.

\begin{tabular}{|lllll|}
\hline Age in years & Primary infertility & \multicolumn{2}{c|}{ Secondary infertility } \\
\hline$<20$ & 6 & 12 & 1 & 2 \\
\hline $21-25$ & 18 & 36 & 7 & 14 \\
\hline $26-30$ & 6 & 12 & 4 & 8 \\
\hline 31 and above & 4 & 8 & 4 & 8 \\
\hline
\end{tabular}

In primary infertility cases $65 \%$ patients belongs to active marriage life duration of 2-4 years, while in secondary infertility $81 \%$ of patients belong to marriage life duration of more than 6 years as given in Table 2 .

Table 2: Duration of marriage life in primary and secondary infertility cases.

\begin{tabular}{|lllll|}
\hline \multirow{5}{*}{ Duration } & \multicolumn{4}{l|}{ According to infertility } \\
\cline { 2 - 5 } & Primary infertility & Secondary infertility \\
\cline { 2 - 5 } & Number & $\begin{array}{l}\text { Percentage } \\
(\%)\end{array}$ & Number & $\begin{array}{l}\text { Percentage } \\
(\%)\end{array}$ \\
\hline $2-4$ & 22 & 65 & - & - \\
\hline $5-6$ & 4 & 12 & 3 & 19 \\
\hline Above 6 & 8 & 23 & 13 & 81 \\
\hline
\end{tabular}

Table 3: Causes of infertility.

\begin{tabular}{|lll|}
\hline Causes of Infertility & Number & Percentage (\%) \\
\hline $\begin{array}{l}\text { Ovarian factor (PCOD, } \\
\text { Ovarian cyst, Endo. cyst) }\end{array}$ & 18 & 36 \\
\hline $\begin{array}{l}\text { Tubal factor (Occlusion, } \\
\text { anomaly, T. O. mass) }\end{array}$ & 13 & 26 \\
\hline $\begin{array}{l}\text { Uterine factor (Congenital } \\
\text { Anomalies, fibroid) }\end{array}$ & 5 & 10 \\
\hline Pelvic Pathology & 11 & 22 \\
\hline
\end{tabular}


Among 50 patients, 14 (28\%) had absolutely normal laparoscopic findings. Among the various pathologies, ovarian pathology contributed the most $(36 \%)$, followed by tubal $(26 \%)$, pelvic $(22 \%)$ and uterine (10\%) pathologies as given in Table 3.

Table 4: Various pathologies of pelvic organ responsible for infertility in patients.

\begin{tabular}{|lll|}
\hline $\begin{array}{l}\text { Uterine } \\
\text { factors- } \mathbf{n}(\%)\end{array}$ & $\begin{array}{l}\text { Tubal } \\
\text { factors }\end{array}$ & Ovarian factors \\
\hline $\begin{array}{l}\text { Normal- } 45 \\
(90 \%)\end{array}$ & $\begin{array}{l}\text { Normal- } \\
37(74 \%)\end{array}$ & Normal- 32 (64\%) \\
\hline $\begin{array}{l}\text { Congenital } \\
\text { anomaly-2 } \\
(4 \%)\end{array}$ & $\begin{array}{l}\text { Abnormal } \\
\text { occlusion- }\end{array}$ & $\begin{array}{l}\text { Bilateral polycystic } \\
\text { ovary- 14 (28\%) }\end{array}$ \\
\hline $\begin{array}{l}\text { Fibroid- } 3 \\
(6 \%)\end{array}$ & $\begin{array}{l}\text { Other pathology (simple } \\
\text { ovarian cyst, chocolate } \\
\text { cyst)- 4 (8\%) }\end{array}$ \\
\hline
\end{tabular}

Table 4 demonstrated the various pathologies diagnosed in 50 patients. Among uterine factors, in the present study maximum number of patients was observed with normal uterine cavity (90\%). Only fibroids were observed in 3 patients followed by congenital anomalies in 2 patients. And next among the tubal factors, abnormal occlusion was observed in $13(26 \%)$ cases and remaining were observed with normal findings 37 (74\%). Bilateral polycystic ovaries were observed in 14 (28\%) cases among ovarian pathologies followed by other pathologies in $4(8 \%)$ cases including ovarian cyst, chocolate cyst, adhesion, or endometriotic implants. In present study, typical pelvic adhesions were found in among 11 (22\%) patients and about 2 patients had Koch's abdomen.

\section{DISCUSSION}

Infertility is a worldwide problem affecting 8-12 percent couple (50-80 million) during their reproductive lives. ${ }^{9}$ The WHO estimates the overall prevalence of primary infertility in India to be between $3.9-16.8 \%$. ${ }^{10}$ The female factors contribute most (i.e. $40-55 \%$ ) in the etiologies of infertility followed by male factors (30$40 \%)$, both partners $(10 \%)$ and unexplained $(10 \%) .{ }^{11}$

Diagnostic laparoscopy is considered as an essential and valuable step of the infertility evaluation. It allows the surgeon to visualize tubal patency and integrity, endometriosis and pelvic adhesions. ${ }^{12}$ Laparoscopy is an important complementary tool to HSG in determining the extent and subsequent therapy for tubal disease.

In our study a total of 50 infertile women were included in the study. The mean age at presentation in our study was 26.5 years (in the range of $21-25$ years) in primary infertility (36\%) and 30 years (range of 26-30 years) in secondary infertility group (12\%) i.e. just beyond the maximum fertile period of life. This was consistent with the observations of Sholapurkar et al. ${ }^{13}$ According to Kanal Sharma's study maximum cases of infertility
$(45 \%)$ are in the age group of $21-25$ years followed by $35 \%$ of cases of infertility in the age group of 26-30 years. $^{14}$

Maximum number of patients $(65 \%)$ presented with less than 2-4 years of primary infertility while $13(81 \%)$ patients out of 21 had duration of more than 6 years of secondary infertility. The study by Waseem et al found the same to be 4.3 years and 6.1years respectively. It is also reported that most common etiological factor too was ovarian. ${ }^{15}$

Ovarian pathology (36\%) and tubal blockage (26\%) was found to be the most common cause of infertility followed by pelvic adhesions (22\%). Cystic ovaries, endometriosis, chocolate cyst, adhesion, or endometriotic implants were also seen. These findings were similar to the study conducted in Thailand by Sinawat et al. ${ }^{16}$

\section{CONCLUSION}

Diagnostic laparoscopy helps in identifying the hidden etiology of infertility so that a therapeutic intervention can be initiated, by avoiding unnecessary empiric medical treatment for ovulation induction. In some patients, diagnostic laparoscopy alters treatment plans, including earlier utilization of assisted reproductive technology. Thus, diagnostic laparoscopy can be safely used earlier in the evaluation of infertile females.

\section{Funding: No funding sources}

Conflict of interest: None declared

Ethical approval: The study was approved by the Institutional Ethics Committee

\section{REFERENCES}

1. Hammond MG. Evaluation of the infertile couple. Obstet Gynecol Clin North Am. 1987;14:821-30.

2. Shaheen R. Infections \& Infertility. IJPD. 2005;2(5):11-2.

3. Jose Miller AB, Boyden JW, Frey KA. Infertility. Am Fam Physician. 2007;75:849-56.

4. Howkins, Bourne. The pathology of conception. In: Shaw's textbook of Gynaecology. $13^{\text {th }}$ edition. Elsevier; 2004.

5. Mehmood S. An audit of diagnostic laparoscopies for infertility. J Surg Pak. 2003;8:8.

6. Rehana R, Majid SS. Aetiological factors of infertility. J Postgrad Med Inst. 2004;18:166-71.

7. Sharon EM, Henry CL, Ruth BL, Lynn MW, Amin AM, Alan MG. Fertil Steril. 2009;92(2):471-80.

8. Wani QA, Ara R, Dangroo SA, Beig M. Diagnostic Laparoscopy in the Evaluation of Female Factors in Infertility in Kashmir Valley. Int J Women's Health Reproduction Sci. 2014;2(2):48-57.

9. World Health Organization. WHO/MCH/91.9. Geneva: World Health Organization; 1991. Infertility: A Tabulation of Available Data on Prevalence of Primary and Secondary Infertility. 
10. Rutstein SO, Macro ORC, Shah IH. Infecundity, infertility, and childlessness in developing countries. DHS Comparative Reports No 9. Calverton, Maryland, USA: ORC Macro and the World Health Organization, 2004.

11. Speroff L, Marc AF. Female infertility: Clinical Gynecologic Endocrinology and Infertility. 7th edition. Jaypee Brothers Medical Publishers; 2005;1013-1068.

12. Cohen SM. Operative Laparoscopy and Hysteroscopy. 2nd edition. Michigan: Churchill Livingstone; 1996.

13. Sholapurkar ML, Sardesai SP, Nalgirkar AJ. A onetime laparoscopic procedure for evaluation of infertile women. J Obstet Gynec India. 1985;35:571.
14. Kanal P, Sharma S. Study of Primary Infertility in females by Diagnostic Laparoscopy. IJMU.2006;1(2):7-9.

15. Waseem T, Mohammad I, Maimoona H, Mohammad S. Infertile Female. Laparoscopic evaluation. Professional Med J. 2007;14(4):562-6.

16. Sinawat S, Pattamadilok J, Seejorn K. Tubal abnormalities in Thai infertile females. J Med Assoc Thai. 2005;88(6):723-7.

Cite this article as: Panchal DN, Shah A. Role of diagnostic laparoscopy in infertility. Int J Reprod Contracept Obstet Gynecol 2016;5:4180-3. 